THE EUROPEAN JOURNAL OF LIFE WRITING VOLUME IX (2020) LW\&D.CM83-LW\&D.CM84

\title{
We all got Poetry and Life is Rich
}

\begin{abstract}
James Morland
Queen Mary University of London

Death? Oh. Aye. Uh.

I disarm, ease the tension, bring the laughter. We both take a deep breath of this air thick and stilted with death-talk. I recount the cycles of atoms that started the research, disguising the root of all of this: my own grief. 'I am the researcher of cycles of death and grief continually stuck in cycles of death and grief' is perhaps not the best clearer of the air.

It is only after the fact that this has all finally revealed itself. This work began with death, continued through deaths, and ends with life. Returning to the poetry of grief with tears running down my face:
\end{abstract}

[...] look back on these tears, also, which, stricken with love, I pour out in memory of you; this is all I can do, while my only wish is to mourn at your tomb and address these empty words to your silent ashes.

Looking back on these texts, they are all memories of you. The chapters have been punctuated by phone calls and funerals. A work on philosophical cycles of life and death has become its own biography of family life and death. The words are anything but empty, the spaces and pauses marry sadness and joy. Each caesura disrupts my forced continued rhythms to just keep on going and writing and going and writing. Do not mourn in the darkness of solitude, return as soon as possible to the daylight of the world and society. Reflecting alone on family mortality whilst surrounded by books on our hour of death, a history of death, on death and anxiety, on the Greek way of death. But there is joy in these darkened texts. Together in the darkness I find a society of the grief-stricken, there are shared pauses to mourn the loss.

The daylight of society is broached too soon in the communal kitchen surrounded by our students as the promise of tears burns my sinuses. In a moment of inherent understanding you save me with a whispered 
affirmation: It's really hard, isn't it. Your embrace shelters me from the complete exposure, the caesura in your whisper mimicking the rhythms I spend my hours tracing. The synchronicities cause a smiling exhale to seep some pressure from the valve. These eighteenth-century rhythms mimic my own cycles of tears and laughter. Pain precedes relief, pressure and release.

You all became the poetry, your ashes are not silent and you sing through the lines. These are our death-songs and this is my afterlife writing, marching through the vales of life and strife and death in the valleys with the world connecting around me.

Synchronicities flower. You never got those years of wonder but I got you and you got me and we all got poetry and life is rich.

Each reading is a bit of me, a bit of you, a continual reminder that nothing is permanent and made all the more wonder-filled because of it. 'Death is inevitable', I pronounce to the room. Cheerfully, joyfully. The Blakean trumpeter floating the veil of death over the skeletons in the room. Each description of the cycles is an affirmation to everyone in the room (or maybe just to myself). A continual reminder that loss precedes finding. I am finding words, finding synchronicities, finding my biography of tears and joy in an eighteenth-century graveyard.

I lost you, but found this cycle of wonder.

\section{ABOUT THE AUTHOR}

James Morland is a postdoctoral research fellow at Queen Mary University of London, where he is a part of the Wellcome-funded 'Pathologies of Solitude, 18th-21st Century' project (207863/Z/17/Z). 